Review Article / Derleme

\title{
Noncommunicable Diseases as A New Urban Epidemic
}

\section{Yeni Bir Kentsel Epidemi Olarak Bulaşıcı Olmayan Hastalıklar}

Gülay Yılmazel ${ }^{* 1}$, Fevziye Çetinkaya ${ }^{2}$, Melis Naçar ${ }^{2}$, Zeynep Baykan ${ }^{2}$

\begin{abstract}
Prevalence of non-communicable diseases has shown an increase in rapidly urbanizing population. It introduces us with a new urban epidemic which shapes by lifestyle and working patterns of urban residents. Physical inactivity, unhealthy diet, smoking and alcohol consumption are four key risk factors which lead the development of non-communicable diseases. Socio-economic, environmental and occupational influence which are brought together with urban settlement increases the impacts of these factors. Air pollution, problems in the food system, lack of green space and living in poor neighbourhoods are important urban features which can trigger noncommunicable diseases. Type 2 diabetes, cardio-vascular diseases, depression, anxiety, chronic obstructive pulmonary disease, cancer, and arthritis are among the noncommuncable disease which can be associated with urban features. Improving urban features, strengthening the city's residents, ensuring community involvement, adapting urban planning and primary health care according to these interventions and implementation of the multi-sectoral strategy may be useful for control and prevention of these diseases.
\end{abstract}

Key words: Urban, epidemic, non-communicable disease

\section{ÖZET}

Bulaşıcı olmayan hastalıkların prevalansı hızla kentleşen nüfusta artış göstermektedir. $\mathrm{Bu}$ durum kent sakinlerinin yaşam biçimi ve çalışma örüntüsü ile şekillenen yeni bir kentsel epidemiyi karşımıza çıkarmaktadır. Bulaşıcı olmayan hastalıkların gelişiminde öncülük eden dört temel risk faktörü; fiziksel inaktivite, sağlıksız beslenme, sigara içimi ve alkol tüketimidir. Kentsel yerleşimin beraberinde getirdiği sosyo-ekonomik, çevresel ve mesleksel etkiler bu risk faktörlerinin etkisini artırmaktadır. Hava kirliliği, gıda sistemindeki sorunlar, yeşil alanların azlığı ve yoksul semtlerde yaşam bulaşıcı olmayan hastalıkları tetikleyebilen önemli kentsel özelliklerdendir. Tip 2 Diyabet, kardiyo-vasküler hastalıklar, depresyon, anksiyete, kronik obstrüktif akciğer hastalığı $(\mathrm{KOAH})$, kanserler ve artritler kentsel özellikler ile ilişkili olabilen bulaşıcı olmayan hastalıklardandır. Bu hastalıkların kontrolü ve önlenmesinde sürdürülebilir kalkınma hedefleri doğrultusunda kentsel özelliklerin iyileştirilmesi, kent sakinlerinin güçlendirilmesi, toplumsal katılımın sağlanması, kentsel planlamanın ve birinci basamak sağlık hizmetlerinin bu müdahale alanlarına göre uyarlanması ile çok sektörlü stratejilerin uygulanması yararlı olabilir.

Anahtar kelimeler: Kent, epidemi, bulaşıcı olmayan hastalık

Received Date / Geliş tarihi: 15.05.2018, Accepted Date / Kabul tarihi: 12.07.2018

${ }^{1}$ Doç.Dr. Hitit Üniversiesi Sağlık Bilimleri Fakültesi, Çorum, TÜRKIYE

${ }^{2}$ Prof.Dr. Erciyes Üniversitesi Tıp Fakültesi, Halk Sağlı̆ı Anabilim Dalı, Kayseri, TÜRKIYE

*Address for Correspondence / Yazışma Adresi: Gülay Yılmazel, Hitit Üniversitesi Sağlık Bilimleri Fakültesi, Çorum, TÜRKIYE

E-mail: dryilmazelgul@gmail.com

Yılmazel G, Çetinkaya F, Naçar M, Baykan Z. Yeni Bir Kentsel Epidemi Olarak Bulaşııı Olmayan Hastalıklar. TJFMPC, 2019;13(1):

$75-84$.

DOI: $10.21763 /$ tjfmpc. 528035 


\section{GíRiş}

Yaşlanan nüfusla ilişkili olan demografik dönüşüm sağlı panoramasını bulaşıcı hastalıklardan bulaşıcı olmayan hastalıklara doğru değiştirmiştir. ${ }^{1}$ Yirmi birinci yüzyılın hızla gelişen bir sağlık tehdidi olarak bulaşıcı olmayan hastalıklar yılda yaklaşık 38 milyon ölümden sorumlu olup, dünya genelinde tüm ölümlerin \%68'ini oluşturmaktadır. Bulaşıcı olmayan hastalıklar içerisinde en fazla paya (yıllık 17,5 milyon ölüm) kardiyovasküler hastalıklar sahiptir. Bunu sirasıyla kanserler (yıllık 8,2 milyon ölüm), solunum sistemi hastalıkları (yıllık 4 milyon ölüm) ve diyabet (yıllık 1,5 milyon ölüm) izlemektedir. Uzun ömürlülük ve sağlıklı yaşlanabilme yeteneği üzerinde de etki bırakan bulaşıcı olmayan hastalıklar nedeniyle gerçekleşen ölümlerin \%52'si prematür ölümdür. $\mathrm{Bu}$ prematür ölümlerin dörtte üçünün kardiyovasküler hastalıklar, kanserler, diyabet ve kronik solunum yolu hastalığı nedeniyle geliştiği belirtilmektedir. $^{2}$ Ülkemizde de bulaşıcı olmayan hastalıkların yükü artmakla birlikte toplam hastalık yükündeki etkisi \%81'dir. 2013 yılında Yeti Yitimine Ayarlanmış Yaşam Y1lına (Disability Adjusted Life Years; DALY) neden olan ilk beş hastalık arasında ilk sırada iskemik kalp hastalığı yer almaktadır. ${ }^{3}$

Bulaşıcı olmayan hastalıkların yükselen prevalansı hızla kentleşen nüfus bağlamında önemli yer tutmaktadır. Dünya-da kentsel nüfusun yılda ortalama \%2,6 oranında artış gösterdiği ve 2050 yılında toplam nüfusun \%70'ini oluşturacağı beklenmektedir. ${ }^{4} \mathrm{Bu}$ hastalıklar şehirlerde sadece insan sağlığını tehdit etmekle kalmayı aynı zamanda ekonomik uygulamalar üzerinde de önemli etkiye sahiptir. Bireylerin ve ailelerin ekonomik pozisyonları üzerindeki olumsuz etkisi nedeniyle finansal güçlüğe ve yoksulluğun kısır döngüsüne yol açmaktadır. ${ }^{5}$ $\mathrm{Bu}$ derleme çalışması bulaşıcı olmayan hastalıkların kentsel bölgelerde bir epidemi haline dönüşmesinin altında yatan faktörlerin belirlenmesi ve bu faktörlerin kontrol altına alınmasında atılacak adımların ortaya konulması amacıyla yapılmıştır.

\section{GEREÇ VE YÖNTEM}

$\mathrm{Bu}$ derleme PubMed, ISI-Web of Science gibi uluslar arası veri tabanlarına ve ULAKBIM ulusal veri tabanına "kentleşme", "kentleşme ve sağlık, "kentleşme ve bulaşıcı olmayan hastalıklar" anahtar sözcükleri girilerek konu ile ilgili makalelerin toplanıp, elde edilen bilgilerin özetlenmesi ile elde edildi. Ayrıca
Dünya Sağlık Örgütü (DSÖ)'nün, Hastalık Kontrolü ve Önleme Merkezleri (CDC)'nin ve Birleşmiş Milletler (UN)'in raporlarından yararlanıld1.

\section{Bulaşıcı Olmayan Hastalıklarda Kentsel Risk Faktörleri}

Şehirler çoklu sağlık sorunları ile karşı karşıya kalmaktadır. Bulaşıcı hastalıklar açısından risk oluşturmalarının yanı sıra kentsel yerleşimcilerin yaşam biçimi ve çalışma örüntüsü ile şekillenen yeni bir kentsel epidemiyi karşımıza çıkarmaktadır. Tipik olarak "zengin" hastalığı olarak düşünülen bulaşıcı olmayan hastalıklar, günümüzde gelişmekte olan ülkelerde ve kentsel gecekondu bölgelerinde pek çok insanın ölümüne neden olmaktadır. ${ }^{2,6}$ Davranıșsal ve çevresel risklerle bağlantılı olarak iyi planlanmayan kentsel barınma, ulaşım ve gıda sistemleri, sosyal ve yaşam biçimi faktörleri bulaşıcı olmayan hastalıklarda epidemiye yol açmaktadır. ${ }^{2,7}$

Bulaşıcı olmayan hastalıkların gelişiminde öncülük eden temel risk faktörleri; artmıs kan basıncı, fiziksel inaktivite, sağlıksız beslenme, sigara içimi ve alkol tüketimidir. Sağlığın sosyal bir belirleyicisi olan kentsel yerleşimin beraberinde getirdiği sosyoekonomik, çevresel ve mesleksel etkiler bu risk faktörlerinin etkisini artırmaktadır. 2,8,9 Bulaşıcı olmayan hastalıklarda kentsel risk faktörleri Şekil 1'de gösterilmiştir.

\subsection{Fizyolojik Risk Faktörleri}

\section{Artmıs kan basıncı}

Koroner arter hastalığı, iskemik ve hemorajik inme için büyük bir risk faktörü olan artmış kan basincı küresel düzeyde 7,5 milyon ölümden ve toplam hastalı yükünün \%3,7'sinden sorumludur. 10 Yürünebilir semtlerin kan basıncını düşürdüğü ve hipertansiyon insidansını azalttı $\breve{g}_{1}$ belirtilmektedir. ${ }^{11}$ Öte yandan, hava kirliliğinin yüksek düzeyde olduğu bölgelerde yaşayanlarda hipertansiyon insidansının ve prevalansının yüksek olduğu gösterilmiştir. ${ }^{12}$ Gürültü kirliliği, suç ișleme oranlarının yüksekliği, yoksulluk ve sosyal etkileşim azlığ kentsel bölgelerde kan basıncını artırabilen diğer faktörlerdir. ${ }^{13}$

\section{Fazla kiloluluk ve obezite}

Çarpık kentleşmenin ikamet yoğunluğu, karışık arazi kullanımı ve bölgenin sosyo- 
ekonomik pozisyonu ile gençler ve yetişkinlerde fazla kiloluluk veya yüksek beden kitle indeksi (BKİ) ile tutarlı bir şekilde ilişkili olduğu, daha az çarpıklaşmanın, daha iyi arazi kullanımının ve daha yüksek sosyoekonomik durumun fazla kilolu ve obez olma açısından daha düşük risk getirdiği raporlanmıştır. 13-16 Kentsel çarpıklaşma beslenme ve fiziksel aktivite kaynaklarına erişilebilirliği azaltabilir. ${ }^{16}$

\section{Yüksek kan kolesterollü}

Yüksek düzeydeki hava ve gürültü kirliliği ile sosyo-ekonomik zorluklar dislipidemi ile yakından ilişkidir. ${ }^{13}$ Buna karşın Avustralya'da yapılan iki çalışmada yüksek kan kolesterol düzeyi ile yürüyebilirlik, kamuya açık alanlar ve gıda çevresi arasında bir ilişki bulunmamıştır. ${ }^{17,18}$

\subsection{Davranışsal Risk Faktörleri}

\section{Fiziksel inaktivite}

Kentsel çevrenin özellikleri fiziksel aktiviteyi hem kolaylaştırabilir hem de sınırlandırabilir. Genel olarak, yetişkinler arasında daha yüksek fiziksel aktivite düzeyleri (özellikle yürüyüş) ile ilişkili olduğu yaygın bir biçimde raporlanan kentsel özellikler; semtlerde yeşil alanlara daha iyi erişim, daha fazla yürüyebilirlik, ticaret / hizmetler / işyerlerine daha iyi erişim, yürüyüş ve bisiklete binmek için daha fazla imkan / alt yapı, daha fazla karma arazi kullanımı (kültürel, ticari, sanayi ve eğlenme alanlarının entegrasyonu) ve daha yükssek çevre kalitesi şeklinde açıklanmaktadır. 19-24

\section{Alkol kullanımı}

Alkol satış noktalarının daha yoğun ve sosyal sermayenin daha yoksul olduğu alanlarda ergenler ve yetişkinler arasında alkol kullanımının daha fazla olduğuna ilişkin kanitlar mevcuttur. ${ }^{19,25,26}$

\section{Sigara}

Yerel çevrenin üç unsurunun sigara içme davranışını etkileyebileceği potansiyeli üzerinde durulmaktadır. Bunlar; tütünün elde edilebilirliği, sosyal sermaye ve uygulamaları ile tütün satış yerlerine yönelik politikalardır. ${ }^{27}$ Yeni Zelanda, Avustralya, İskoçya ve Amerika'da yapılan çalışmalarda tütün satış noktalarının daha yoğun olduğu semtlerde sigara içme prevalansının daha yüksek olduğu ortaya konulmuştur. ${ }^{28-32}$

\section{Madde ve teknoloji bağımlılığı}

Kent yerleşimcileri bulaşıcı olmayan hastalıklara davetiye çıkaran davranışsal tetikleyiciler açısından da risk altındadır. $\mathrm{Bu}$ tetikleyiciler arasında madde bağımlılı̆̆ teknoloji bağımlılığı günümüz şehirleri için ciddi bir halk sağlığı tehdidi haline gelmiştir. Semtin sosyal çevresi ile kişilerin madde kullanım örüntüleri arasında yakın ilişki olduğu belirtilmektedir. Psiko-sosyal stresörler, sosyal destek azlığı ve suç olayları bağımlılık riskini artırmaktadır. Psikiyatrik bozukluklar her iki bağımlılık türü için yaygın komorbiditedir. ${ }^{33-35}$

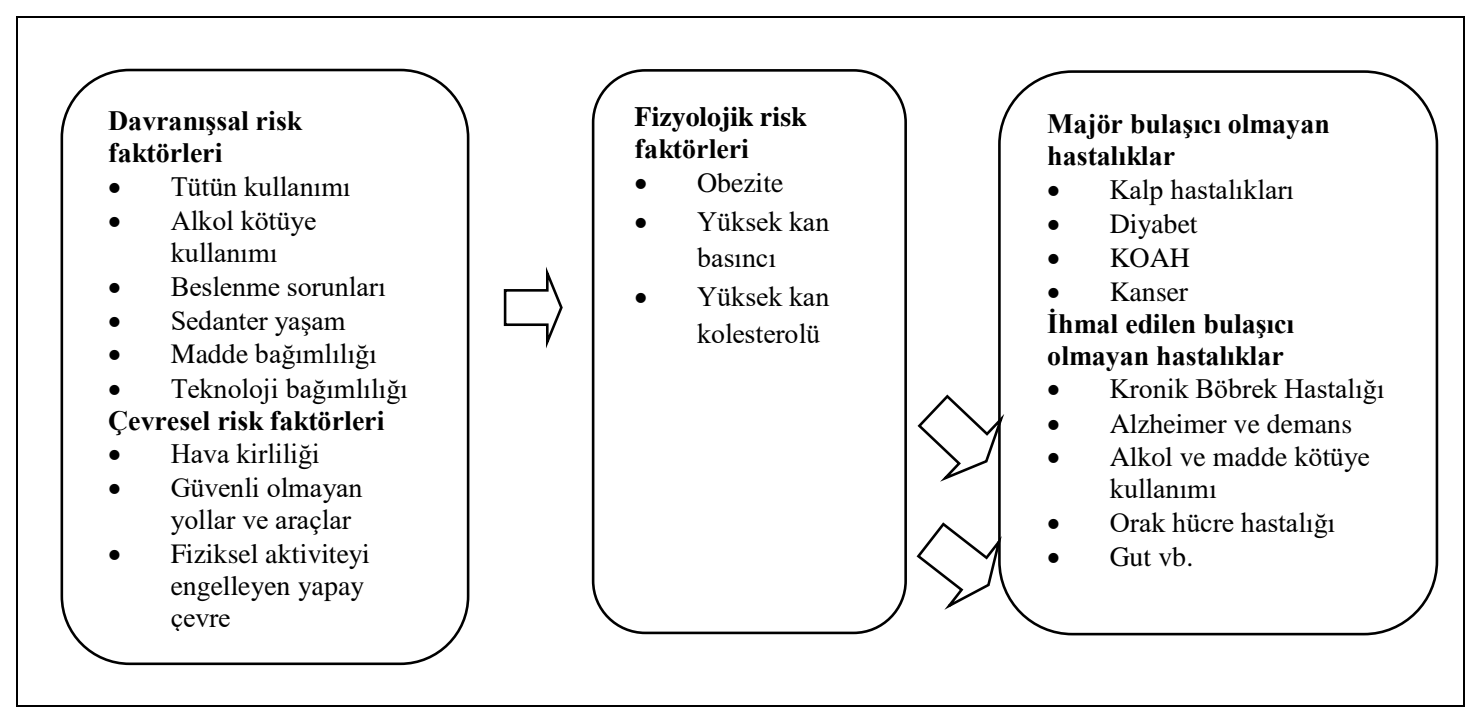

Şekil 1. Bulaşıcı olmayan hastalıklarda kentsel risk faktörleri 


\section{Bulaşıcı Olmayan Hastalıklar ve Kentsel Özellikler}

Tip 2 Diyabet (DM), kardiyo-vasküler hastalıklar (KVH), ruhsal bozukluklar, $\mathrm{KOAH}$, kanserler ve artritler kentsel özellikler ile daha fazla ilişkili olduğu gösterilen bulaşıcı olmayan hastalıklar arasında yer almaktadır. Bulaşıcı olmayan hastalıklarla ilişkili kentsel özellikler Şekil 2'de gösterilmiştir.

\subsection{Tip 2 Diyabet}

Amerika ve Hollanda'da yapılan üç büyük kesitsel araştırmada semt yeşil alanlarının varlığ1 ile Tip 2 DM görülme sıklığı arasında ters ilişki bulunmuştur. ${ }^{36,37}$ Konuyla ilgili yapılan prospektif çalışmalarda ise yürümeye elverişli semtlerde yaşayanlarda Tip 2 DM ve pre-diyabetin gelişme riskinin daha düşük olduğu gösterilmiştir. ${ }^{18,38,39}$ Hava kirliliği Tip 2 DM için risk olarak gösterilen diğer bir kentsel özelliktir. Dış ortam hava kirliliğine uzun süreli maruziyetin Tip $2 \mathrm{DM}$ görülme sıklığını ve gelişme riskini az da olsa artırdığı gösterilmiştir. ${ }^{40,41}$

Tip 2 DM ile besin çevresi arasındaki ilişkinin incelendiği çalışmalarda farklı kanıtlar mevcuttur. Amerika'da 10,763 kişiyi kapsayan bir çalışmada gıda satış noktalarının (süpermarketler, manavlar ve hazır gıda satış noktaları) yakınında yaşama ile Tip 2 DM prevalansı arasında anlamlı bir ilişki bulunmamıştır. Buna karşın, Kaliforniya'da 43000 kişinin telefon anketine katıldığı başka bir çalışmada ise fast-food restoranlarına ve hazır gıda satış noktalarına erişebilme ile kişilerin beyan ettiği yüksek Tip 2 DM prevalansı arasında anlamlı bir ilişki olduğu gösterilmiştir. ${ }^{42,43}$ Semt yoksunluğu Tip 2 DM insidansı ile ilişkili olan diğer bir unsurdur. Dezavantajlı semt sakinlerinin Tip 2 DM'ye sahip olma olasılı̆̆ daha az dezavantajlı semtlerde yaşayanlara göre 1.8 kat daha yüksek bulunmuştur. ${ }^{44}$

\subsection{Kardiyo-vasküler Hastalık}

Yeni Zelanda Sağlık Araştırmasında (2006/2007), semtlerin yeşil alan oranları ile KVH gelişme riski arasında ilişki olduğu, daha az yeşil alanlarda $(<\% 16)$ yaşayanlarla kıyaslandığında yeşil alan oranı \%33,3- \%69,8 olan semtlerde KVH riskinin anlamlı ölçüde düşük olduğu gösterilmiştir. ${ }^{45}$ Öte yandan yüksek trafik gürültüsü ve yoğunluğu $\mathrm{KVH}$ morbiditesi ile ilişkilendirilmektedir. İsveç'te yapılan bir vaka-kontrol çalışmasında uzun süre yüksek düzeyde trafik gürültüsüne maruz kalanlarda miyokard infarktüsü riskinin 1,4 kat daha yüksek olduğu saptanmıştır. ${ }^{46}$ Diş ortam hava kirliliğine maruz kalma ile KVH arasında ilişki olduğunu gösteren çalışmalar da mevcuttur. Hava kirleticilerine (karbonmonoksit, sülfür dioksit, nitrojen dioksit, $\mathrm{PM}_{2.5}$ ve $\mathrm{PM}_{10}$ ) k1sa süreli ( $\leq 7$ gün) maruz kalmanın kalp yetmezliği, inme ve miyokard infarktüsü riskinde artış ile sonuçlandığ1 gösterilmiştir. ${ }^{47,48}$

Amerika'da semtlerde fast food restoranlarının sayısı ile iskemik inme prevalansı arasındaki ilişki 1247 kişinin katıldı ̆̆ 1 kesitsel bir çalışmada gözlemlenmiştir. Fast-food restoranlarının fazla sayıda olduğu semtlerde iskemik inme riskinin \%13 oranında daha yüksek olduğu gösterilmiştir. 49 Öte yandan çarpık kentleşmeye karşın daha düzenli bir kentsel bölgede yaşayanların kardiyovasküler olay, ölüm veya miyokard infarktüsü geçirme riskinin daha düşük olduğu saptanmıştır. ${ }^{50}$ Amerika'da yaşlı bireylerde kalp problemleri insidansının incelendiği bir çalışmada ekonomik açıdan dezavantajlı bölgelerde yaşayan kadınlarda kalp problemlerinin gelişme olasılığı $\% 20$ daha yüksek bulunmuştur. ${ }^{51}$

\subsection{Ruhsal Bozukluklar}

Kentsel çevrenin çeşitli mekanizmalarla ruh sağlığını etkilediği ileri sürülmektedir. Depresyon/veya anksiyete bozukluğu tanısı almış kişilerde yapılan çalışmalarda çeşitli kentsel özellikler (kirletilmiş çevre, yeşil alan azlığı, yoksul semtler, şiddet) ile bazı ruh sağlığı göstergeleri (psikolojik stres, ruhsal sağlık algısı, depresif belirtiler vb.) arasında anlamlı ilişki olduğu gösterilmiştir. ${ }^{52,53}$

\section{4. КОАН}

Küresel düzeyde KOAH gelişiminin \%9'undan çevresel hava kirliliği sorumlu tutulmaktadır. ${ }^{54}$ En az yoksunluğun olduğu semtlere göre en çok yoksun semtlerde yaşayanlarda $\mathrm{KOAH}$ tanısı alma olasılı̆̆ının 2 kattan fazla olduğu belirtilmiştir. ${ }^{55}$ Semt yoksunluğu ve KOAH arasındaki ilişki sağlıksız yaşam biçimi davranışlarının (sigara içme, fiziksel inaktivite, yetersiz beslenme vb.) yoksun bölgelerde yaşayanlarda sık görülmesinden kaynaklanabilir.

\subsection{Kanserler}

Akciğer kanseri 
Yüksek düzeyde havadaki kirleticilerine maruz kalanlarda akciğer kanseri riskinin yüksek olduğu saptanmıştır. ${ }^{56}$ Akciğer kanserlerinin \%14'ü çevresel hava kirliliğine atfedilmektedir. ${ }^{54}$ Amerika'da suç ve ayrımcılığın yüksek olduğu bir bölgede yaşayanlarda kanser gelişme olasılığının yüksek olduğu gösterilmiştir. ${ }^{51}$

\section{Meme kanseri}

Genetik ve üreme ile ilgili faktörlerin ötesinde kentleşme ve yaşam biçimi meme kanseri vakalarının artmasında anahtar bir role sahiptir. Sigara içimi, alkol kullanımı, sedanter yaşam ve obezite meme kanseri için değiştirebilir risk faktörlerindendir. ${ }^{57}$

\section{Kolo-rektal kanser ve prostat kanseri}

Vücut ağırlığının fiziksel hareketsizlikle birlikte en s1k görülen kanserlerin beşte biri ile üçte birinden sorumlu olduğu tahmin edilmektedir. ${ }^{58}$ Yetersiz düzenli fiziksel aktivite, obezite, alkol tüketimi, sigara kullanımı, aşırı yağlı ve posa açısından zayıf beslenme şekli, sebze ve meyve tüketim azlığı kolo-rektal kanser riskinde artışa yol açmaktadır. ${ }^{59}$ Prostat kanserinin etiyolojisinde rol oynayan risk faktörleri arasında davranışsal (sigara içimi, hayvansal yă ve kırmızı et tüketimi, yağlı ve enerji yoğun beslenme şekli, obezite) ve mesleki (pestisit ve manyetik alan maruziyeti) riskler almaktadır. ${ }^{60-63}$

\section{Deri kanseri}

Yeşil alan ve sağlık arasındaki muhtemel ilişkinin her zaman olumlu olmadığı belirtilmektedir. Nitekim yaklaşık 267 bin Avustralyalının dâhil edildiği bir çalışmada bireysel değişkenler kontrol edildikten sonra (dişarıda geçirilen zamanlar da dâhil) daha yeşil bölgelerde yaşayanlarda deri kanserinin rölatif riskinin daha yüksek olduğu saptanmıştır. ${ }^{32}$ Kentsel özellikler ile kanser arasındaki ilişki incelendiğinde kanserlerin etyolojisindeki farklılıklar da göz önünde bulundurulmalidir.

\subsection{Artritler}

Semt yoksunluğu ile artritlerin görülme sıklığ1 arasında ilişki olduğu, en dezavantajlı semt sakinlerinde daha az dezavantajlı semtlerde yaşayanlara göre artritlerin daha sık görüldüğü raporlanmıştır. ${ }^{64}$

\section{7. İhmal Edilen Bulaşıcı Olmayan Hastalıklar}

Bilinen geleneksel risk faktörlerinin yanı sıra ortaya çıkışında hava kirliliği, malnutrisyon, kötü hijyen, işsizlik, gecekondu yaşamı ve diğer çevresel maruziyetlerin rol aldığ 1 ihmal edilen bulaşıcı hastalıklar da mevcuttur. İhmal edilen bulaşıcı olmayan hastalıklar dört büyük hastalığa (diyabet, KOAH, kanserler ve kardiyo-vasküler hastalıklar) göre hastalık yükünde daha fazla paya sahiptir. Unutulan bu hastalıklar arasında alkol ve madde kötüye kullanımı, karaciğer sirozu, astım, kronik böbrek hastalığı, Alzeimer ve diğer bunamalar, orak hücreli anemi, gut, bel ve boyun ağrıları, peptik ülser, konjenital anomaliler ve hemoglobinopatiler gösterilmektedir. ${ }^{65,66,67}$

\section{Bulaşıcı Olmayan Hastalıklarla Yakından İlişkili Diğer Durumlar}

\subsection{Engellilik}

Küresel düzeyde erişkin nüfusta engellilik prevalansının \%15,6-19.4 arasında değiştiği tahmin edilmektedir. ${ }^{68}$ Engelli bireylerde engellilik ile ilişkili en yaygın sağlık sorunları arasında bulaşıcı olmayan hastalıklar yer almaktadır. 69 Engellilerde yapılan bir çalışmada engellilik ile ilişkili olarak saptanan sağlık sorunları arasında kalp hastalığı, hipertansiyon, diyabet, görme bozuklukları, akciğer ve solunum problemleri, kırıklar, inme ve duyma bozuklukları gösterilmiştir. 70 Engelli bireylerin sağl1k durumu çevresel faktörlerden etkilenmektedir. $\mathrm{Bu}$ faktörler; yoksulluk, yetersiz sanitasyon, malnutrisyon, sağlık hizmetlerine erişim eksikliği, fiziksel çevre engelleri, trafik kazaları, ulaşım sistemindeki sorunları şeklinde sıralanabilir. ${ }^{69}$

\subsection{Güvenlik ve Şiddet Olayları}

Yüksek suç ve ayrımcılığın olduğu bölgelerde yaşayanlarda kanser veya malign tümör gelişme riskinin yüksek olduğu, semt stresörlerinden güvenlik ve şiddet olaylarına orta derecede maruz kalanlarda ise koroner kalp hastalığ 1 riskinin $\% 50$ daha yüksek olduğu gösterilmiştir. ${ }^{71}$

\subsection{Trafik Kazaları}

Kent sağlı̆̆ kaos" olarak tanımlanan trafik kazalarını kent sakinlerinin sağlığı ile bütünleştirmek gerekmektedir. Dünya genelinde her y1l 50 milyon kişinin trafik kazalarına bağlı sakatlık ve yaralanmalardan etkilendiği ve yaklaşık 1,5 milyon kişinin öldüğü belirtilmektedir. Trafikte araç sayısının artması, yaşam biçimi 


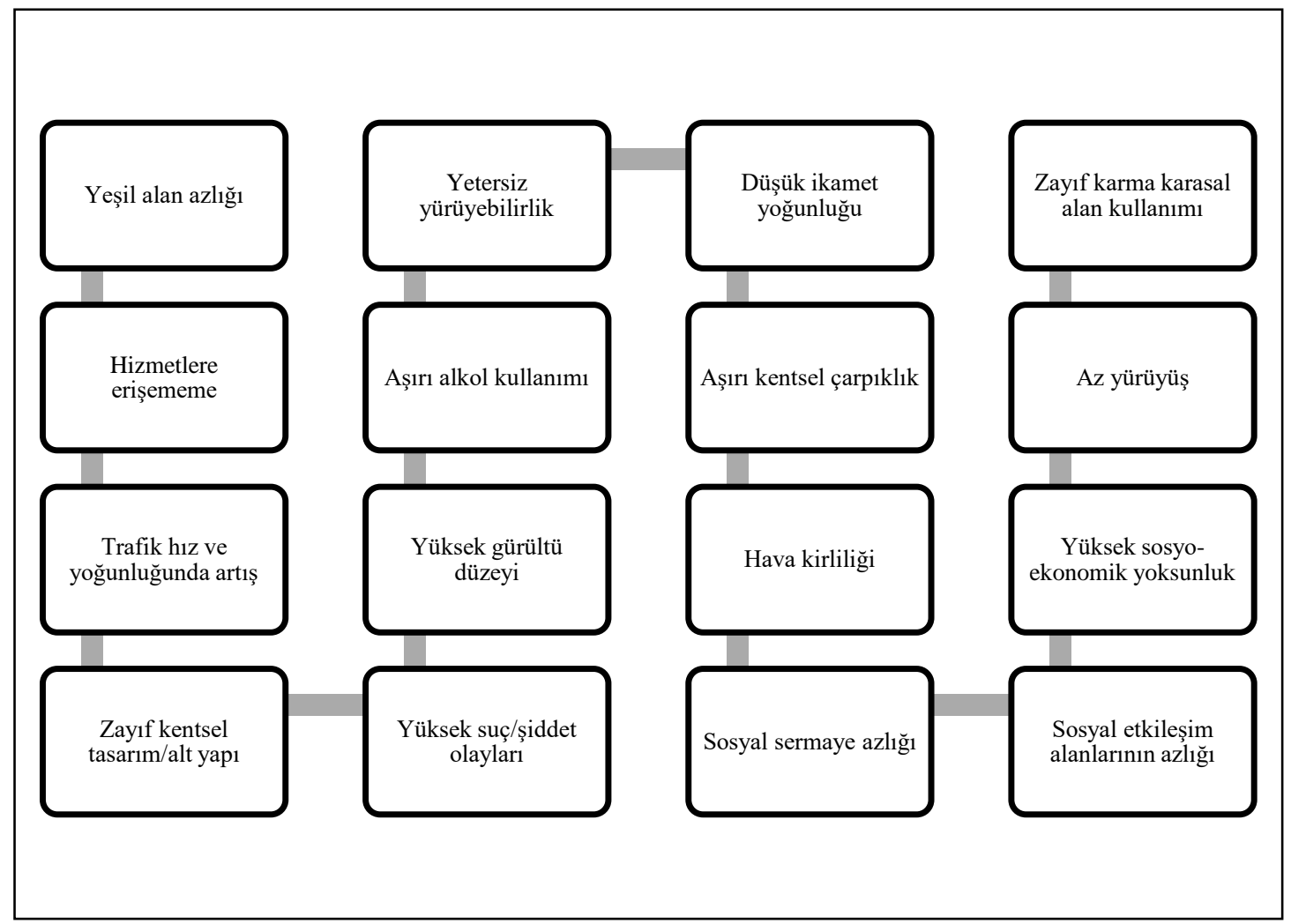

\section{Şekil 2. Bulaşıcı olmayan hastalıklarla ilişkili kentsel özellikler}

\section{Kentlerde Bulaşıcı Olmayan Hastalıklarla Mücadele}

Kentler çeşitli özelliklerinden dolayı bulaşıcı olmayan hastalıkları tetikleyebilir ya da var olan hastalıkları derinleştirebilir. Özellikle yoksulluk ve sağlıkta eşitsizlikler ulusal ve küresel düzeyde hastalık yükünün önemli bir bölümüne katkıda bulunmaktadır. Kentlerin sağlığa zarar veren davranışlar ile bulaşıcı olmayan hastalıklara nasıl yol açtığını anlamada ve sağlıkta eşitliğe erişimde sürdürülebilir kalkınma hedefleri anahtardır. Birleşmiş Milletler'in Eylül 2015 tarihinde yapmış olduğu bir zirvede" Sürdürülebilir Kalkınma İçin 2030 Gündemi” den 17 sürdürülebilir kalkınma hedefi dünya liderleri tarafindan 1 Ocak 2016 tarihinde benimsenmiştir. Sürdürülebilir kalkınma hedefleri "kimseyi arkanda bırakma" amaci ile yoksulluğun sona erdirilmesi, eşitsizlikle savaş, eğitim, sağlık, sosyal koruma, iş imkanları, çevresel koruma ve iklim değişikliği ile mücadele konularında tüm ülkeleri harekete geçirme çabalarını içerir. $\mathrm{Bu}$ hedeflerden Hedef 11: "Sürdürülebilir Şehirler ve Toplum Hedefinde belirtilen göstergeler yol gösterici kabul edilmektedir. $\mathrm{Bu}$ göstergeler dokuz başlıkta toplanmaktadır:2,74
1.Ulaşım ve hareket

2.Arazi kullanım planlaması ve peyzaj tasarımı

3.G1da sistemleri

4.Enerji

5.Barınma

6.Temiz su ve atık yönetimi

7.İşyerleri ve çalışanların sağlığı

8.Gecekondu bölgelerini daha iyi konuma getirmek

9.Yeşil alanları artırma

\section{SONUC}

Bulaşıcı olmayan hastalıklar kent sağlığının önemli ölçütlerinden biridir. Yaşlanan nüfus, sosyo-ekonomik eşitsizlikler, hızlı kentleşme, tütün kullanımı, fiziksel inaktivite ve sağlıksız beslenme, alkol ve madde bağımlılığı, teknoloji bağımlılığı kentlerde bulaşıc1 olmayan hastalıkların epidemi düzeyinde görülmesine yol açan önemli müdahale alanlarıdır. Kentsel özellikler sağlıkla ilgili davranışlar ve sağlık sonuçları üzerinde oldukça etkilidir. Kent sağlığını geliştirebilecek müdahaleler; yeşil alanların artırılması, yürüyüş ve bisiklet sürüşü için alt yapıların oluşturulması, etkili ulaşım sistemlerinin kullanılması, toplumda eşitsizliklerin azaltılması, toplumsal 
kaynaklara (eğitim, sağlık, ulaşım, iletişim, meslek vb.) erişimin artırılması, barınma koşullarının iyileştirilmesi, temiz ve güvenilir enerji sistemlerinin kullanımı şeklinde sıralanabilir. Bulaşıcı olmayan hastalıkların morbiditesinin azaltılmasinda toplumsal önceliklerin ve gereksinimlerin belirlenmesi önemli bir halk sağlığı imajıdır. Bu doğrultuda "Sürdürülebilir Kalkınma Hedefleri" özellikle koruyucu hekimlik hizmetinde çalışanlara yol gösterici olabilecektir. Kentsel bölgelerin planlamasında kent yöneticileri ile eşgüdümle hareket edilmesi sağlık, ekonomik ve çevresel yararların bütüncül yaklaşımla incelenmesi kent sağlığını yükseltecektir. Aynı zamanda kent sakinlerinin güçlendirilmesi, toplumsal katılımın sağlanması, birinci basamak sağlık hizmetlerinin bu müdahale alanlarına göre yeniden uyarlanması yararlı olabilir.

\section{KAYNAKLAR}

1. World Health Organization. Our cities, our health, our future. Acting on social determinants for health equity in urban settings. World Health Organization, 2016. Erişim: http://www.who.int/social determinants/ publications/urbanization/en/. Erişim tarihi:22.12.2017.

2. World Health Organization. Global report on urban health: equitable, healthier cities for sustainable development. World Health Organization, 2016. Erişim: http://www.who.int/kobe_centre/ measuring/urban-global-report/en/. Erişim tarihi:22.12.2017

3. T.C. Sağlık Bakanlığı ve Hacettepe Nüfus Etütleri Enstitüsü. Ulusal Hastalık Yükü Çalışması 2013. Erişim: http://www.hips.hacettepe.edu.tr/UHYCS unumu_ 06122016.pdf. Erişim tarihi: 22.12.2017.

4. UN Department of Economic and Social Affairs, Population Division. World Urbanization Prospects, the 2011 Revision. Erişim: http://esa.un.org/unup/. Erişim tarihi:22.12.2017.

5. World Economic Forum and World Health Organization. From burden to "best buys": reducing the economic impact of non-communicable diseases in low- and middle-income countries. Cologny/ Geneva, 2011. Erişim: http://apps.who.int/ medicinedocs/documents/ s18804en/s18804en. pdf. Erişim tarihi: 22.12.2017.

6. Snyder RE, Rajan JV, Costa F, Lima H, Calcagno JL, Couto RD, et al. Differences in the prevalence of non-communicable disease between slum dwellers and the general population in a large urban area in Brazil. Trop Med Infect Dis 2017; 47 (2):1-12.

7. World Health Organization. Urban Health. Erişim: http://www.who. int/mediacentre/ news/releases/ 2010 / urban health 20100407/en/. Erişim tarihi: 22.12.2017.

8. Htet AS, Bjertness MB, Sherpa LY, Kjøllesdal MK, Oo WM, Meyer HE, et al. Urban-rural differences in the prevalence of non-communicable diseases risk factors among 25-74 years old citizens in Yangon Region, Myanmar: a cross sectional study. BMC Public Health 2016; 16: 1225.

9. Oommen AM, Abraham VJ, George K, Jose VJ. Prevalence of risk factors for non-communicable diseases in rural \& urban Tamil Nadu. Indian J Med Res 2016; 144: 460-71.

10. World Health Organization. Erişim: http://www.who.int/gho/ncd/risk_factors/ blood_pressure_prevalence_text/en/. Erişim Tarihi: 14.06.2018.

11. Sarkar C, Webster C, Gallacher J. Neighbourhood walkability and incidence of hypertension: Findings from the study of 429,334 UK Biobank participants. Int J Hyg Environ Health 2018;221(3):458-468.

12. Giorgini P, Di Giosia P, Grassi D, Rubenfire M, Brook RD, Ferri C. Air pollution exposure and blood pressure: an updated review of the literature. Current Pharmaceutical Design 2016; 22(1): 2851.

13. Leal C, Chaix B. The influence of geographic life environments on cardiometabolic risk factors: a systematic review, a methodological assessment and a research agenda. Obes Rev 2011; 12(3): 217-230.

14. Grasser G, Van Dyck D, Titze S, Stronegger W. Objectively measured walkability and active transport and weight-related outcomes in adults: a systematic review. Int $\mathbf{J}$ Public Health 2013; 58(4): 615-625.

15. De Bourdeaudhuij I, Van Dyck D, Salvo D, Davey R, Reis RS, Schofield G, et al. International study of perceived neighbourhood environmental attributes and Body Mass Index: IPEN Adult study in 12 countries. Int $\mathbf{J}$ Behav Nutr Phys Act 2015; $12: 62$.

16. Feng J, Glass TA, Curriero FC, Stewart WF, Schwartz BS. The built environment and obesity: a systematic review of the epidemiologic evidence. Health Place 2010; 16(2): 175-190. 
17. Müller-Riemenschneider F, Pereira G, Villanueva K, Christian H, Knuiman M, Giles-Corti B, et al. Neighborhood walkability and cardiometabolic risk factors in Australian adults: an observational study. BMC Public Health 2013; 13: 755.

18. Paquet C, Coffee NT, Haren MT, Howard NJ, Adams RJ, Taylor AW, et al. Food environment, walkability, and public open spaces are associated with incident development of cardiometabolic risk factors in a biomedical cohort. Health Place 2014; 28: 173-176.

19. Cooper R, Boyko CT, Cooper C. Design for health: the relationship between design and noncommunicable diseases. J Health Commun 2011; 16 (Suppl 2): 134-157.

20. Grasser G, Van Dyck D, Titze S, Stronegger W. Objectively measured walkability and active transport and weight-related outcomes in adults: a systematic review. Int $\mathbf{J}$ Public Health 2013; 58(4): 615-625.

21. Lachowycz K, Jones AP. Greenspace and obesity: a systematic review of the evidence. Obes Rev 2011; 12(5): e183189

22. McCormack GR, Shiell A. In search of causality: a systematic review of the relationship between the built environment and physical activity among adults. Int $\mathbf{J}$ Behav Nutr Phys Act 2011; 8: 125.

23. Sugiyama T, Neuhaus M, Cole R, GilesCorti B, Owen N. Destination and route attributes associated with adults' walking: a review. Med Sci Sports Exerc 2012; 44(7): 1275-1286.

24. Van Holle V, Deforche B, Van Cauwenberg J, Goubert L, Maes L, Van de Weghe N, et al. Relationship between the physical environment and different domains of physical activity in European adults: a systematic review. BMC Public Health 2012; 12: 807

25. Bryden A, Roberts B, Petticrew M, McKee M. A systematic review of the influence of community level social factors on alcohol use. Health Place 2013; 21: 70-85.

26. Gmel G, Holmes J, Studer J. Are alcohol outlet densities strongly associated with alcohol-related outcomes? A critical review of recent evidence. Drug Alcohol Rev 2016; 35(1):40-54.

27. Bowie C, Beere P, Griffin E, Campbell M, Kingham S. Variation in health and social equity in the spaces where we live: a review of previous literature from the
GeoHealth Laboratory. New Zealand Sociology 2013; 28(3): 164.

28. Lipperman-Kreda S, Mair C, Grube JW, Friend KB, Jackson P, Watson D. Density and proximity of tobacco outlets to homes and schools: relations with youth cigarette smoking. Prev Sci 2014; 15(5):738-744.

29. Marashi-Pour S, Cretikos M, Lyons C, Rose N, Jalaludin B, Smith J. The association between the density of retail tobacco outlets, individual smoking status, neighbourhood socioeconomic status and school locations in New South Wales, Australia. Spat Spatiotemporal Epidemiol 2015; 12: 1-7.

30. Pearce J, Rind E, Shortt N, Tisch C, Mitchell R. Tobacco retail environments and social inequalities in individual-level smoking and cessation among Scottish adults. Nicotine Tob Res 2016; 18(2): 138-146.

31. Shortt NK, Tisch C, Pearce J, Richardson EA, Mitchell R. The density of tobacco retailers in home and school environments and relationship with adolescent smoking behaviours in Scotland. Tob Control 2016; 25(1): 75-82.

32. Astell-Burt T, Feng X, Kolt GS. Neighbourhood green space and the odds of having skin cancer: multilevel evidence of survey data from 267072 Australians. J Epidemiol Community Health 2014; 68(4): 370-374.

33. Lin EY, Witten K, Casswell S, You RQ. Neighbourhood matters: perceptions of neighbourhood cohesiveness and associations with alcohol, cannabis and tobacco use. Drug Alcohol Rev 2012; 31(4): 402-412.

34. Chandra PS, Shiva L, Nanjundaswamy MH. The impact of urbanization on mental health in India. Curr Opin Psychiatry 2018;31 (3):276-281.

35. Bozkurt $\mathrm{H}$, Şahin $\mathrm{S}$, Zoroğlu S. İnternet Bağımlılığı: Güncel Bir Gözden Geçirme. Journal Of Contemporary Medicine 2016;6(3):235-247.

36. Bodicoat DH, O'Donovan G, Dalton AM, Gray LJ, Yates T, Edwardson C, et al. The association between neighbourhood greenspace and type 2 diabetes in a large cross-sectional study. BMJ Open 2014; 4(12): e006076.

37. Maas J, Verheij RA, de Vries S, Spreeuwenberg P, Schellevis FG, Groenewegen PP. Morbidity is related to a green living environment. J Epidemiol Community Health 2009; 63(12): 967973. 
38. Booth GL, Creatore MI, Moineddin R, Gozdyra P, Weyman JT, Matheson FI, et al. Unwalkable neighborhoods, poverty, and the risk of diabetes among recent immigrants to Canada compared with long-term residents. Diabetes Care 2013; 36(2): 302-308.

39. Christine PJ, Auchincloss AH, Bertoni AG, Carnethon MR, Sánchez BN, Moore $\mathrm{K}$, et al. Longitudinal associations between neighborhood physical and social environments and incident type 2 diabetes mellitus: the Multi-Ethnic Study of Atherosclerosis (MESA). JAMA Internal Medicine 2015; 175(8): 1311-1320.

40. Eze IC, Hemkens LG, Bucher HC, Hoffmann B, Schindler C, Künzli N, et al. Association between ambient air pollution and diabetes mellitus in Europe and North America: systematic review and metaanalysis. Environ Health Perspect 2015; 123(5): 381-389.

41. Wang B, Xu D, Jing Z, Liu D, Yan S, Wang Y. Effect of long-term exposure to air pollution on type 2 diabetes mellitus risk: a systemic review and meta-analysis of cohort studies. Eur J Endocrinol 2014; 171(5): 173-182.

42. Morland K, Diez Roux AV, Wing S. Supermarkets, other food stores, and obesity: the atherosclerosis risk in communities study. Am J Prev Med 2006; 30(4): 333-339.

43. California Center for Public Health Advocacy. Designed for disease: the link between local food environments and obesity and diabetes: detailed methodology. Los Angeles: PolicyLink, UCLA Center for Health Policy Research. Erişim:

http://healthpolicy.ucla.edu/publications/D ocuments/

PDF/Designed\%20for\%20Disease\%20Th e\%20Link\%20Between\%20Local\%20Foo d\%20Environments\%20and\%200besity\% 20and\%20Diabetes\%203.pdf. Erişim tarihi: 05.01.2018.

44. Rachele JN, Giles-Corti B, Turrell G. Neighbourhood disadvantage and selfreported type 2 diabetes, heart disease and comorbidity: a cross-sectional multilevel study. Ann Epidemiol 2016; 26(2): 146150.

45. Richardson E, Pearce J, Mitchell R, Kingham S. Role of physical activity in the relationship between urban green space and health. Public Health 2013; 127(4): 318-324.

46. Selander J, Nilsson ME, Bluhm G, Rosenlund M, Lindqvist M, Nise G, et al.
Longterm exposure to road traffic noise and myocardial infarction. Epidemiology 2009; 20(2): 272-279.

47. Shah AS, Langrish JP, Nair H, McAllister DA, Hunter AL, Donaldson $\mathrm{K}$, et al. Global association of air pollution and heart failure: a systematic review and meta-analysis. Lancet 2013; 382(9897): 1039-1048.

48. Martinelli N, Olivieri O, Girelli D. Air particulate matter and cardiovascular disease: a narrative review. Eur J Intern Med 2013; 24(4): 295-302.

49. Morgenstern LB, Escobar JD, Sánchez BN, Hughes R, Zuniga BG, Garcia N, et al. Fast food and neighborhood stroke risk. Ann Neurol 2009; 66(2): 165-170.

50. Griffin BA, Eibner C, Bird CE, Jewell A, Margolis K, Shih R, et al. The relationship between urban sprawl and coronary heart disease in women. Health Place 2013; 20: 51-61.

51. Freedman VA, Grafova IB, Rogowski J. Neighborhoods and chronic disease onset in later life. Am J Public Health 2011; 101(1): 79-86.

52. Alegría M, Molina KM, Chen CN. Neighborhood characteristics and differential risk for depressive and anxiety disorders across racial/ethnic groups in the United States. Depress Anxiety 2014; 31(1): 27-37.

53. Richardson R, Westley T, Gariépy G, Austin N, Nandi A. Neighborhood socioeconomic conditions and depression: a systematic review and meta-analysis. Soc Psychiatry Psychiatr Epidemiol 2015; 50(11): 1641-1656.

54. Prüss-Ustün A, Wolf J, Corvalán C, Bos R, Neira M. Preventing disease through healthy environments: a global assessment of the burden of disease from environmental risks. Geneva, Switzerland: World Health Organization, 2016. Erişim: http://www.who.int/quantifying_ehimpact s/publications/ preventingdisease/en/. Erişim tarihi: 19.01.2018.

55. Jordan KP, Hayward R, Roberts E, Edwards JJ, Kadam UT. The relationship of individual and neighbourhood deprivation with morbidity in older adults: an observational study. Eur J Public Health 2014; 24(3): 396-398.

56. Hamra GB, Laden F, Cohen AJ, Raaschou-Nielsen O, Brauer M, Loomis D. Lung cancer and exposure to nitrogen dioxide and traffic: a systematic review and meta-analysis. Environ Health Perspect 2015; 123(11): 1107-1112. 
57. Danaei G, Vander Hoorn S, Lopez AD, Murray CJ, Ezzati M. Causes of cancer in the world: comparative risk assessment of nine behavioural and environmental risk factors. Lancet 2005; 366: 1784-93.

58. World Health Organization. Diet, nutrition and the prevention of chronic diseases: report of a joint WHO/FAO expert consultation, Geneva, 2002. WHO technical report series; 916. Erişim: http://apps.who.int/iris/bitstream/handle/1 0665/ 42665/WHO TRS 916.pdf? sequence=1. Erişim Tarihi: 14.06.2018.

59. Centers for Disease Disease Control and Prevention. Erişim: https://www.cdc.gov/cancer/dcpc/data/ind ex.htm). Erişim Tarihi: 14.06.2018.

60. Quiñones LA, Irarrázabal CE, Rojas CR, Orellana CE, Acevedo C, Huidobro C, et al. Asian J Androl_2006; 8(3):349-55.

61. Zhang J, Kesteloot H. Milk consumption in relation to incidence of prostate, breast, colon, and rectal cancers: is there an independent effect? Nutr Cancer 2005; 53(1):65-72.

62. Gun RT, Pratt N, Ryan P, Roder D. Update of mortality and cancer incidence in the Australian petroleum industry cohort. Occup Environ Med 2006; 63(7):476-81

63. Calle EE, Rodriguez C, Walker-Thurmond K, Thun MJ. Overweight, obesity, and mortality from cancer in a prospectively studied cohort of U.S. adults. N Engl J Med. 2003; 348(17):1625-38.

64. Brennan SL, Turrell G. Neighborhood disadvantage, individual-level socioeconomic position, and self-reported chronic arthritis: a cross-sectional multilevel study. Arthritis Care Res 2012; 64(5): 721-728.

65. Nulu S. Neglected chronic disease: The WHO framework on non-communicable diseases and implications for the global poor. Global Public Health 2017;12(4):

66. Lopez AD, Williams TN, Levin A, Tonelli M, Singh JA, Burney PG, et al. Remembering the forgotten noncommunicable diseases.BMC Med 2014; 22(12): 200 .
67. Turan MT, Beşirli A. Kentleşme sürecinin ruh sağlığı üzerine etkileri. Anadolu Psikiyatri Dergisi 2008; 9:238243.

68. World Health Organization. The global burden of disease: 2004 update. Geneva, World Health Organization, 2008. Erişim: http://www.who.int/healthinfo/global bur den_disease/ 2004_report_update/en/. Erişim Tarihi: 14.06.2018.

69. World Health Organization. World report on disability 2011. Erişim: http://www.who.int/disabilities/world_rep ort/2011/en/ .Erişim Tarihi:14.08.2018.

70. Lafortune G, Balestat G. Trends in severe disability among elderly people: assessing the evidence in 12 OECD countries and the future implications [OECD Health Working Papers No. 26]. Paris, Organisation for Economic Co-operation and Development, 2007. Erişim: http://www.oecd.org/dataoecd/13/8/38343 783.pdf. Erişim Tarihi: 14.06.2018.

71. Kershaw KN, Diez Roux AV, Bertoni A, Carnethon MR, Everson-Rose SA, Liu K. Associations of chronic individual-level and neighbourhood-level stressors with incident coronary heart disease: the MultiEthnic Study of Atherosclerosis. J Epidemiol Community Health 2015; 69(2):136-141.

72. Kanchan T, Kulkarni V, Bakkannavar SM, Kumar N, Unnikrishnan B. Analysis of fatal road traffic accidents in a coastal township of South India. J Forensic Leg Med 2012; 19:448-51.

73. World Health Organization. Global status report on road safety: time for action. Erişim:

http://who.int/violence_injury_prevention/ road_safety_status/2009. Erişim tarihi: 14.06.2018.

74. United Nations. Sustainable Development Goals. Erişim: https://www.un.org/sustainabledevelopme nt/sustainable-development-goals/. Erișim Tarihi: 14.06.2018. 